\title{
Giant Cell-Rich Solitary Fibrous Tumor in the Nasopharynx: Case Report and Literature Review
}

This article was published in the following Dove Press journal: OncoTargets and Therapy

\author{
Shuang-Shuang Dong (D* \\ Ning Wang* \\ Cui-Ping Yang \\ Guo-Chang Zhang (D) \\ Wei-Hua Liang \\ Jin Zhao \\ Yan Qi
}

Department of Pathology, Shihezi University School of Medicine and The First Affiliated Hospital to Shihezi University School of Medicine, Shihezi, Xinjiang 832002, People's Republic of China

*These authors contributed equally to this work
Correspondence: Yan Qi; Jin Zhao Department of Pathology, Shihezi University School of Medicine \& the First Affiliated Hospital to Shihezi University School of Medicine, North 2 Road, Shihezi, Xinjiang 832002, People's

Republic of China

Tel +86 I5009932652;

Tel +86 I3579767756

Email qiyanyan-1998@।63.com;

1505108219@qq.com

\begin{abstract}
Solitary fibrous tumors (SFTs) can occur in several locations outside the pleura, but rarely in the sinonasal tract, and particularly not in the nasopharynx. Herein, we describe an unusual case of giant cell-rich SFT (GCRSFT) occurring in the nasopharynx. A 64-yearold man experienced dizziness and headache for more than 10 years with no obvious cause. Computed tomography (CT) scan showed a $3.9 \mathrm{~cm} \times 2 \mathrm{~cm}$ tumor on the posterior lateral wall of the left nasopharynx, and angiography revealed a hypervascular tumor fed by branches of the left carotid artery. Hence, preoperative embolization was performed, and then the tumor was endoscopically resected. The symptoms were relieved after the resection, and postoperative head CT and video laryngoscopy showed that the tumor was completely resected. We next characterized the specific pathological characteristics of the resected tumor. Histologically, the tumor was characterized by varying cellular proliferation of cytologically bland spindle cells within a collagenous stroma, with prominent interspersed branching vessels. Mitotic activity was low (2/50HPF), and there was no evidence of pleomorphism or tumor necrosis. Moreover, multinucleated giant cells with deep nuclear staining and distributed in pseudovascular spaces were found within the tumor. We ruled out the possibility that our case was giant cell fibroblastoma (GCF) by immunohistochemical analysis, showing that the tumor cells were positive for CD34, CD99, STAT6, and BCL-2, and that the Ki-67 labeling index was 3\%, indicating that our case was SFT and not GCF. The patient's condition is generally good after a 14-month follow-up. This report serves to broaden the morphologic spectrum of GCRSFT and will help clinicians and pathologists better understand this entity to prevent misdiagnosis.
\end{abstract}

Keywords: giant cell-rich solitary fibrous tumor, nasopharynx, differential diagnosis

\section{Introduction}

Solitary fibrous tumors (SFTs) are rare tumors of mesenchymal origin, accounting for only $2 \%$ of all soft tissue tumors. ${ }^{1}$ SFTs typically develop in the pleura, but extra-thoracic SFTs can occur in various parts of the body. These tumors do not show a sexual predilection, and the median age of onset is 50 years (range: 20-70 years). ${ }^{2}$ The primary treatment of SFT is surgical resection with negative margins. Tumors that cannot be completely excised or that show malignant histological features may respond to radiation and/or chemotherapy. Giant cell-rich SFT (GCRSFT), formerly known as giant cell angiofibroma (GCA), was first described as a rare orbital tumor in $1995 .^{3}$ However, it has also been reported to occur in the head and neck, back, retroperitoneum, hips, vulva, and groin. ${ }^{4,5}$ SFTs occurring in the nasopharynx are very rare, with only 5 such cases reported till date. ${ }^{6-10}$ To the best of our knowledge, GCRSFT of the nasopharynx has not yet been reported. 
In this study, we present an extremely rare case of GCRSFT in the nasopharynx. SFTs present nearly equally as asymptomatic slow-growing masses or with local symptoms due to compression. The clinical symptoms of SFT in the nasopharynx depend on the tumor size and growth rate, the most common manifestation being ear canal obstruction and nasal obstruction. However, the patient in the current study presented only with dizziness and headache, without ear canal or nasal obstruction. Here, we describe the clinicopathological and immunohistochemical features of this case of GCRSFT and present a literature review. Our data provide important insights into the diagnosis, differential diagnosis, and treatment of GCRSFT in the nasopharynx.

\section{Case Presentation}

A 64-year-old man developed a painless nodule or mass in the nasopharynx. He had a history of dizziness and headache for more than 10 years without obvious cause. The patient also had a history of hypertension. After taking antihypertensive drugs regularly, the headache was relieved. However, the dizziness and headache later increased further for 1 week, and on February 27, 2019, he was admitted to a hospital. The patient underwent surgical treatment for benign prostatic hyperplasia in May 2006. The patient had no history of trauma, no family history of any hereditary illness, and his neurological examination findings were normal.

Head computed tomography (CT) examination showed a low-density mass in the nasopharynx that protruded into the cavity and had a regular shape and uniform density. The left eustachian tube and pharyngeal orifice had disappeared and the right pharyngeal crypt had become shallow (Figure 1A). Video laryngoscopy also revealed a left nasopharyngeal mass. To confirm the diagnosis, enhanced CT of the nasopharynx was performed, revealing a mass-like shadow on the posterior lateral wall of the left nasopharyngeal roof (Figure 1B). The enhanced CT image was very uneven in the arterial phase (Figure 1C) but became intense in the venous phase, and small, patchy, low-density shadows were observed (Figure 1D). Based on the preoperative imaging results, the patient was provisionally diagnosed with nasopharyngeal angiofibroma. Angiography revealed a hypervascular tumor fed by branches of the left carotid artery. To control intraoperative bleeding, the patient underwent preoperative endovascular embolization. Subsequently, the otolaryngologist performed surgical removal of the tumor through a nasal endoscope. During the surgery, it was noticed that the tumor tissue pedicle was located on the posterior lateral wall of the left nasopharyngeal roof. The tumor was completely removed along its pedicle without the occurrence of massive intraoperative hemorrhage. The tumor tissue had a medium texture and abundant blood supply. Postoperative head CT and video laryngoscopy showed that the tumor was completely resected (Figure 1E), and there was no tumor recurrence following a 14-month follow-up after tumor resection.

The resected tumor specimens were fixed in $10 \%$ neutral-buffered formalin and processed for
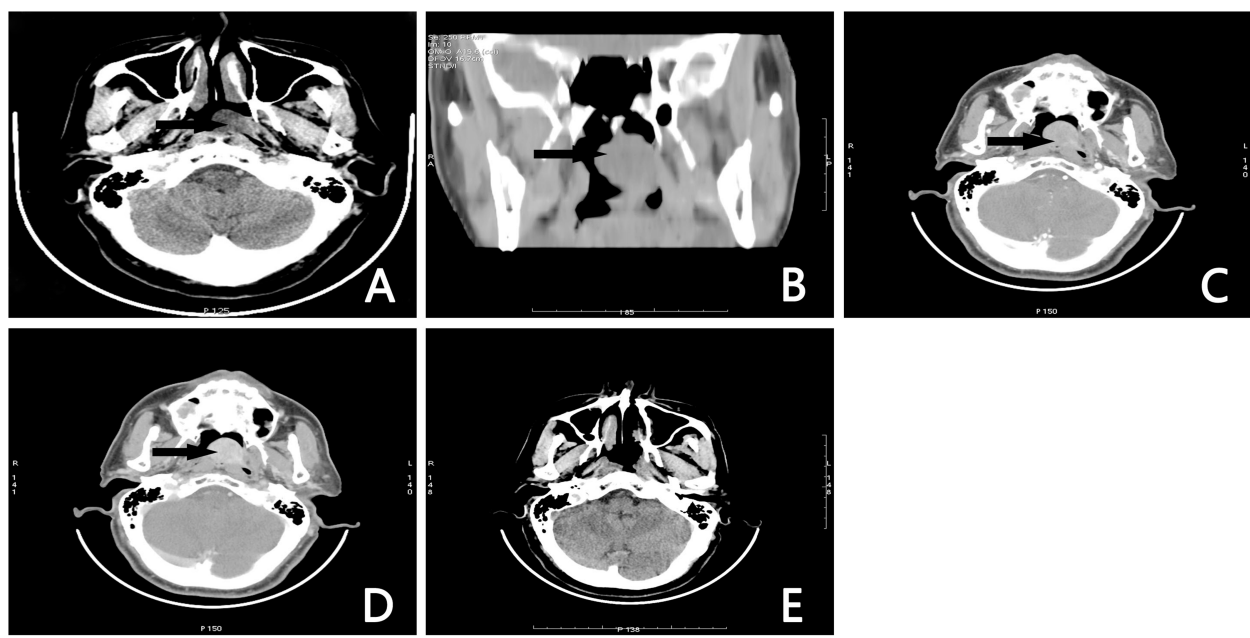

Figure I Preoperative CT scans showing a large tumor in the nasopharynx. (A) Head CT image showing dense mass of nasopharyngeal soft tissue, protruding into the cavity, with regular shape and uniform density. The left eustachian tube and pharyngeal orifice are not visible, while the right pharyngeal crypt appears shallow. (B) Nasopharyngeal CT scan showing a mass-like shadow on the posterior lateral wall of the left nasopharyngeal roof. The enhanced scan image showing uneven density in the arterial phase (C). Areas with intense dye uptake in the venous phase, and small patchy low-density shadows (D). Postoperative head CT showing that the tumor is completely resected (E). 
Table I Antibodies Used in This Case

\begin{tabular}{|l|l|l|l|l|l|}
\hline Antibodies & Clone & Dilution & Source & Location & Result \\
\hline STAT6 & Rabbit Ab & - & ZSGB-BIO & $\mathrm{N}$ & Diffuse positive \\
CD34 & Mouse mAb & $\mathrm{I}: 600$ & ZSGB-BIO & $\mathrm{C}$ & Diffuse positive \\
CD99 & Mouse mAb & $\mathrm{I}: 200$ & ZSGB-BIO & $\mathrm{C}$ & Diffuse positive \\
BCL-2 & Mouse mAb & $\mathrm{I}: 600$ & ZSGB-BIO & M or C & Diffuse positive \\
CD68 & Mouse mAb & $\mathrm{I}: 3000$ & ZSGB-BIO & $\mathrm{C}$ & Partialpositive \\
Ki-67 & Mouse mAb & $\mathrm{I}: 400$ & ZSGB-BIO & Cell & $3 \%$ \\
SMA & Mouse mAb & $\mathrm{I}: 500$ & ZSGB-BIO & $\mathrm{C}$ & Negative \\
EMA & Mouse mAb & $\mathrm{I}: 800$ & ZSGB-BIO & M & Negative \\
S-100 & Mouse mAb & $\mathrm{I}: 1600$ & ZSGB-BIO & $\mathrm{C}$ & Negative \\
MUC-4 & Mouse mAb & $\mathrm{I}: 50$ & ZSGB-BIO & $\mathrm{C}$ & Negative \\
SOX10 & Rabbit mAb & $\mathrm{I}: 800$ & ZSGB-BIO & C & Negative \\
\hline
\end{tabular}

Abbreviations: $N$, nucleus; $C$, cytoplasm; M, membrane.

immunohistochemistry (IHC) following standard protocols. Paraffin-embedded blocks were sectioned at a thickness of $5 \mu \mathrm{m}$ and stained with hematoxylin and eosin, and with various antibodies. The antibody clones, their working dilutions, and commercial sources are listed in Table 1.
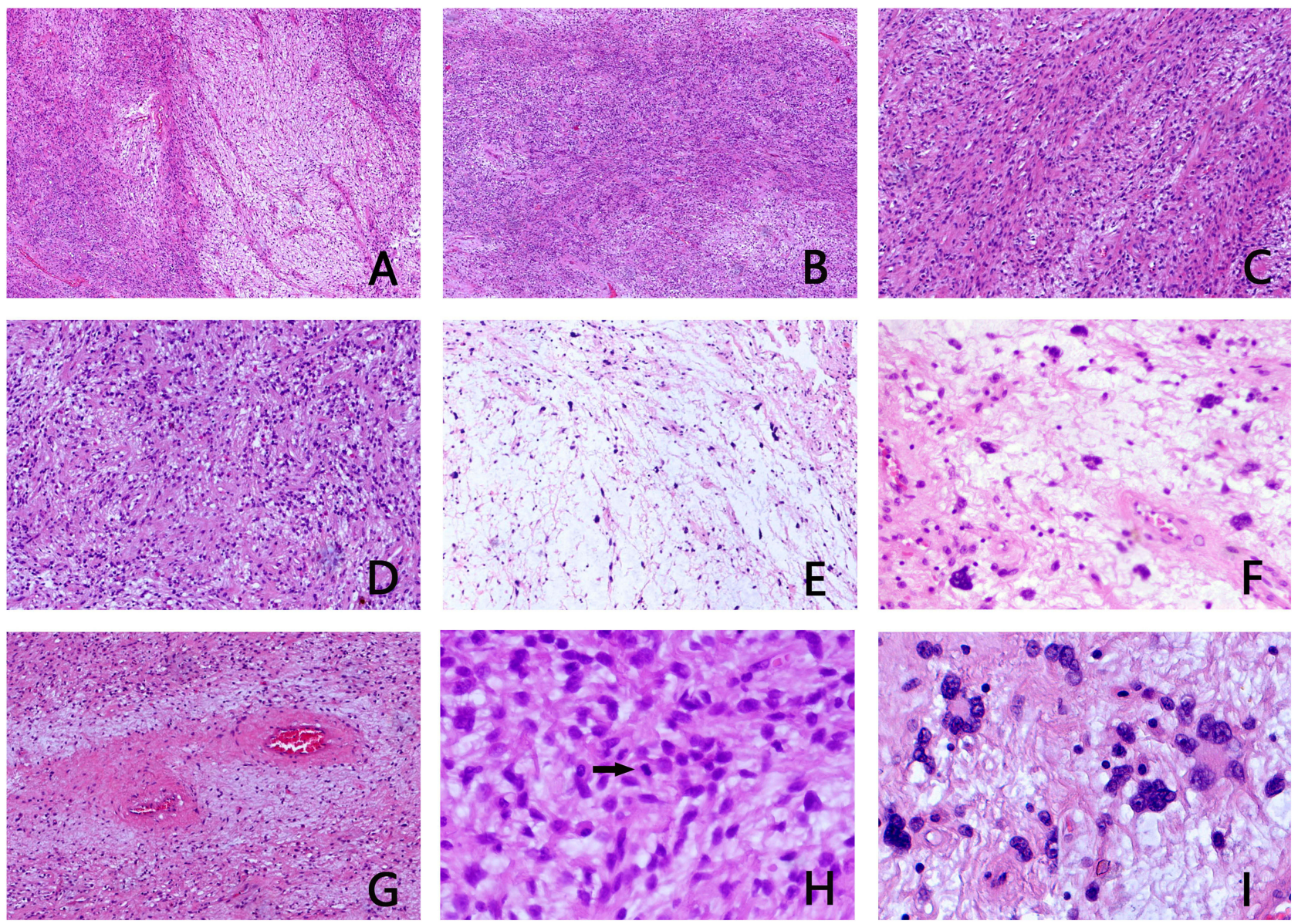

Figure 2 Microphotographs showing the histopathological features of the tumor. (A) Dense areas with cellular proliferation alternating with hypocellular areas (H\&E; $\times 40)$. (B) Area of the tumor showing disorganized cellular arrangement (H\&E; $\times 40)$. (C) Area with tumor cells arranged in stripes (H\&E; $\times 100)$. (D) Area with tumor cells arranged in storiform pattern $(\mathrm{H \& E} \times \mathbf{1 0 0})$. (E) Multinucleated giant cells deposited in a myxoid stroma $(\mathrm{H \& E} ; \times 100)$. (F) Multinucleated giant cells deposited in a hyaline stroma $(\mathrm{H} \& \mathrm{E} ; \times 200)$. (G) Interstitial vessels with hyaline degeneration (H\&E; $\times 100)$. (H) Hypercellular areas showing fusiform or oval cells, with no apparent atypia, few cytoplasm, large and deep stained nuclei, and oval nuclei as well as some vacuolated nuclei and some tumor cells with nucleoli. Mitotic figures were 2 per 50 high-power fields (H\&E; ×400). (I) Multinucleated giant cells varying in size and shape showing nuclei nested in the cytoplasm in a wreath-like and lobulated-shape (H\&E; $\times 400)$. 
In gross examination, the surgically excised tissue in fragments, a tissue size of $6.5 \mathrm{~cm} \times 4.0 \mathrm{~cm} \times 2 \mathrm{~cm}$, was surgically excised, which included the tumor tissue and tissue at the edges of the tumor. Part of the tumor was polypoid-shaped with a firm or gelatinous, white-to-gray colored cut surface. No bleeding or necrosis was noticed.

Histologically, low-power microscopy revealed that the tumor comprised areas of moderately proliferating bland spindle- or stellate-shaped cells alternating with hypocellular areas (Figure 2A). While some areas were composed of compactly proliferating spindle-shaped cells arranged in a storiform or fascicular growth pattern, there were other areas where tumor cells were randomly distributed (Figure 2B-D). Some areas were observed with loose myxoid or hyaline stroma, in which collagen fibers of different thickness and shape were interspersed among multinucleated giant cells (Figure 2E and F), but no necrosis was observed. Interstitial blood vessels were widely distributed with marked perivascular hyalinization (Figure 2G). High-power microscopy revealed hypercellular areas containing fusiform or oval cells, with no apparent atypia, few cytoplasm, large and deep-stained nuclei, and oval nuclei as well as some vacuolated nuclei and some tumor cells with nucleoli. Mitotic figures were 2/50 HPF (Figure 2H). Tumor cells in less cellular dense areas were polygonal or irregular in shape.
They also lacked significant cytologic atypia. In addition, multinucleated giant cells varied in size and shape, with the nuclei mostly nested in the cytoplasm in a wreath-like or lobulated-shape (Figure 2I). The pathological results supported the diagnosis of SFT.

In some areas, tumor cells were arranged in a wavy pattern (Figure 3A), the stroma was apparently myxoid (Figure 3B), and showed significant collagenization. Multinucleated giant cells were found in the pseudovascular spaces (Figure 3C) that were also distributed among the spindle-shaped tumor cells (Figure 3D). These findings were consistent with the characteristics of GCF. Therefore, further evidence was needed to confirm or rule out GCF.

IHC revealed cells that were diffusely positive for $\mathrm{CD} 34$ (Figure 4A), BCL-2 (Figure 4B), and CD99 (Figure 4C), and negative for S100, SOX10, SMA, EMA, and MUC4 (Table 1), supporting the diagnosis of SFT. However, CD34 expression is also a feature of GCF and dermatofibrosarcoma protuberans. Furthermore, nuclear staining for STAT6 by IHC has been shown to be a highly sensitive and specific marker for SFT (Figure 4D). These results helped to differentiate between SFT and GCF. Moreover, IHC for CD68 showed focal cytoplasmic positivity in giant cells (Figure 4E), which is a characteristic of SFT. GCF, on the other hand, is typically characterized by strong and diffuse
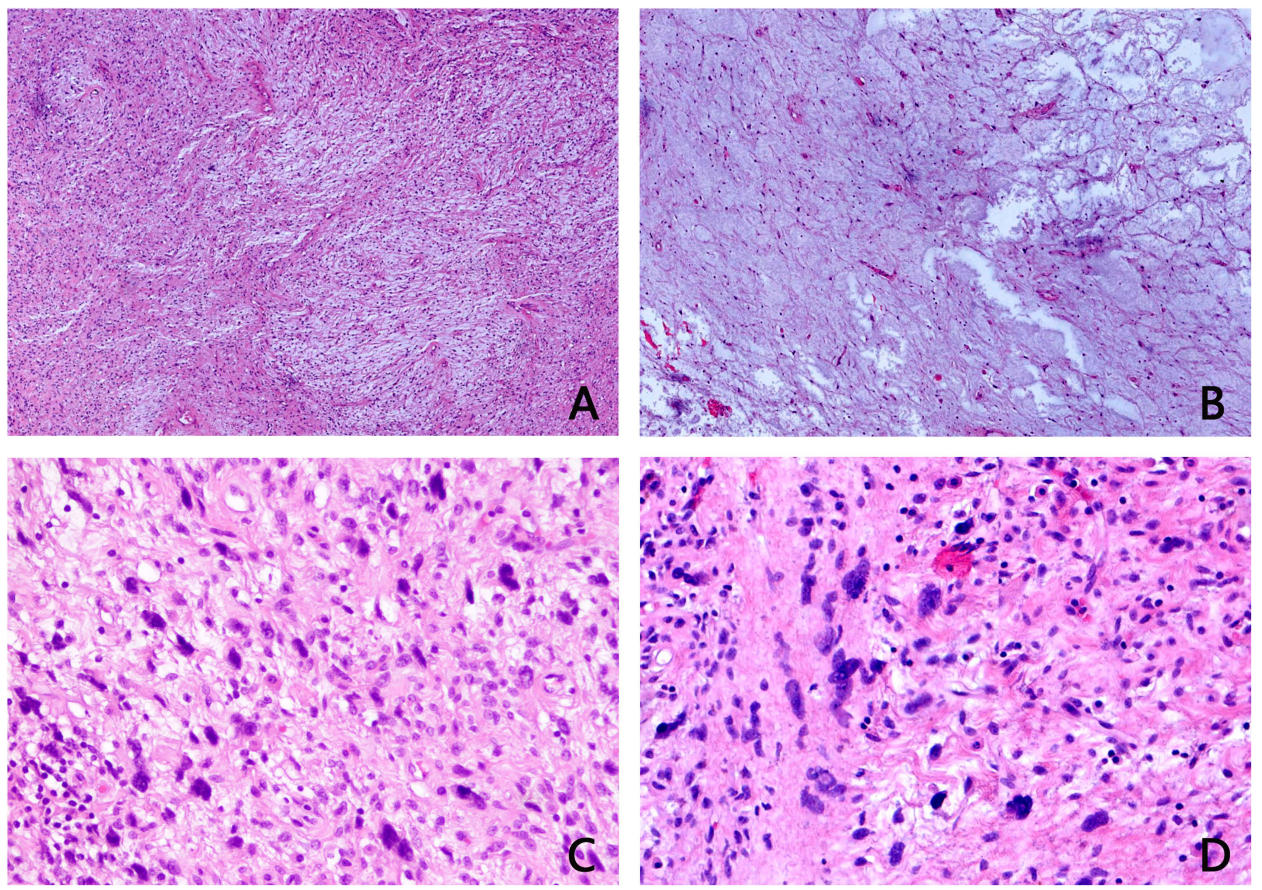

Figure 3 Micrographs showing characteristics of tumor stroma (A) Area showing tumor cells arranged in a wavy pattern (H\&E; $\times 40)$. (B) Area showing apparent myxoid degeneration in the stroma (H\&E; $\times 40)$. (C) Multinucleated giant cells with deep nuclear stains within the pseudovascular space (H\&E; $\times 200)$. (D) Multinucleated giant cells distributed among the spindle tumor cells and the collagenous stroma $(\mathrm{H \& E} \times 200)$. 


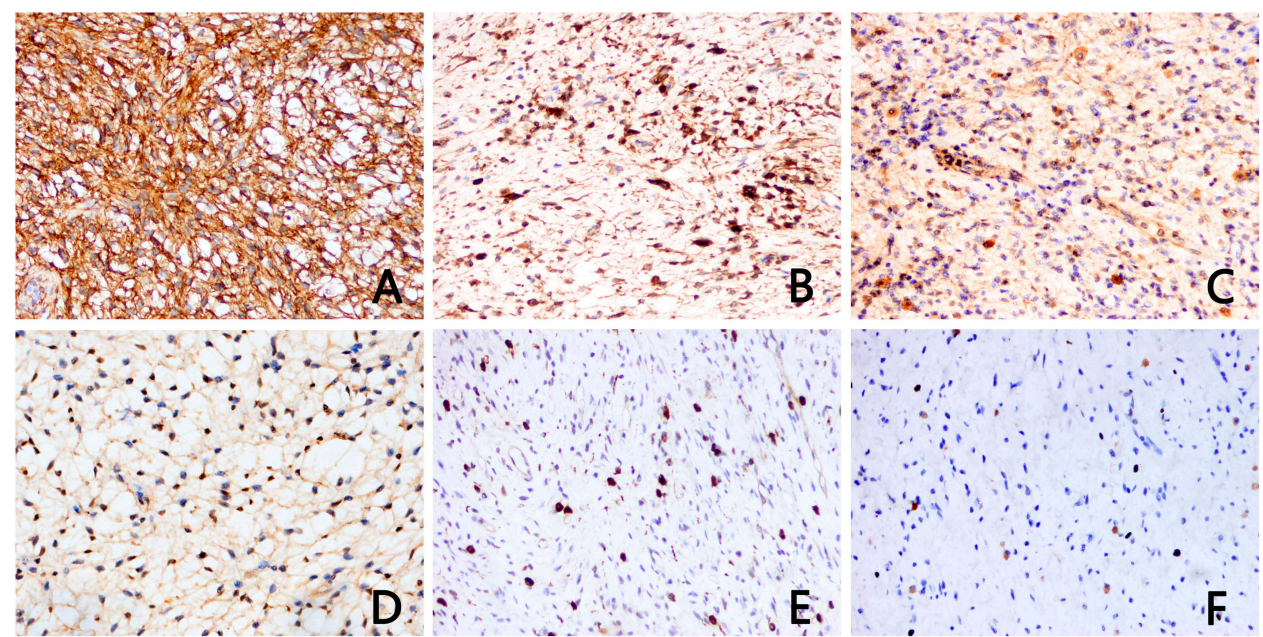

Figure 4 Immunohistochemical analysis of the tumor. (A) IHC image showing cells with diffuse CD34 positivity (original magnification $\times 200$ ). (B) IHC staining for BCL-2 showing diffuse membrane and cytoplasm positivity (original magnification $\times 200$ ). (C) Tumor cells showing diffuse membrane positivity for CD99 (original magnification $\times 200$ ). (D) IHC of STAT6 showing partially flaky nuclear positivity (original magnification $\times 200$ ). (E) IHC of CD68 showing partial cytoplasm positivity in giant cells (original magnification $\times 200$ ). (F) IHC for Ki-67 showing some positively stained cells (labeling index of $3 \%$ ) (original magnification $\times 200$ ).

CD68 expression. In addition, only scattered cells were positive for the proliferative marker Ki-67, with a labeling index of 3\% (Figure 4F). Based on these morphological features and immunohistochemical findings, pathological diagnosis of GCRSFT was made.

\section{Discussion}

SFTs occur predominantly in fibroblastic areas of the pleura. Extra-thoracic SFTs are rare tumors of mesenchymal origin with intermediate biological potential and account for less than $2 \%$ of all soft-tissue tumors. The age of onset for SFT ranges from 20 to 70 years, and the median age of onset is 50 years, with no significant gender differences. Extra-thoracic SFTs have been reported in many sites including the liver, adrenal gland, skin, and the head and neck region. In the head and neck, the literature indicates that this rare tumor has been reported in the oral cavity, orbit, nose and paranasal sinuses, larynx, major salivary glands, and thyroid. ${ }^{11}$ SFTs occurring in the nasopharynx are very rare, with only 5 such cases reported in the literature (Table 2).

Table 2 Review of Reported 5 Cases of Solitary Fibrous Tumor in the Nasopharynx

\begin{tabular}{|c|c|c|c|c|c|}
\hline $\begin{array}{l}\text { Authorl } \\
\text { Year }\end{array}$ & $\begin{array}{l}\text { Agel } \\
\text { Sex }\end{array}$ & $\begin{array}{l}\text { Size } \\
(\mathrm{cm})\end{array}$ & Clinical Presentation & Treatment & Fu \\
\hline $\begin{array}{l}\text { Zheng WJ } \\
(2017)^{6}\end{array}$ & $49 / M$ & 1.7 & Right earplugs without obvious cause for more than I month & $\mathrm{S}$ & NED (NA) \\
\hline $\begin{array}{l}\text { Rizzo } \\
(2015)^{7}\end{array}$ & $26 / M$ & 6.7 & Nasal obstruction, mucopurulent rhinorrhea and frequent epistaxis & $\mathrm{S}$ & $\begin{array}{l}\text { NED (13 } \\
\text { months) }\end{array}$ \\
\hline $\begin{array}{l}\text { Parghane } \\
\text { RV }(20 \mid 4)^{8}\end{array}$ & $3 \mathrm{I} / \mathrm{F}$ & NA & lyear history of nasal obstruction & NA & NA \\
\hline $\begin{array}{l}\text { Ferrario } \\
F(1997)^{9}\end{array}$ & NA & NA & 6 months history of aural fullness at the right ear & $\mathrm{S}$ & NA \\
\hline Job $1(1991)^{10}$ & $45 / M$ & 5 & $\begin{array}{l}5 \text { years history of progressive bilateral nasal obstruction, bilateral loss of hearing } \\
\text { and associated right ear discharge for } 6 \text { months }\end{array}$ & $\mathrm{S}$ & $\begin{array}{l}\text { NED (6 } \\
\text { months) }\end{array}$ \\
\hline Dong SS* & $64 / M$ & 6.5 & $\begin{array}{l}\text { No obvious inducement of dizziness, headache for more than } 10 \text { years, and the } \\
\text { conscious headache worsened for I week }\end{array}$ & $\mathrm{S}$ & $\begin{array}{l}\text { NED (I4 } \\
\text { months) }\end{array}$ \\
\hline
\end{tabular}

Note: *Present case.

Abbreviations: FU, follow-up; F, female; M, male; S, surgery; NA, not available; NED, no evidence of disease. 
The tumor cells have CD34 dendritic mesenchymal cell differentiation, and genetic analysis shows a $12 \mathrm{q}$ rearrangement to form the NAB2-STAT6 fusion gene. ${ }^{12}$ SFT includes four subtypes: classic type SFT, GCRSFT, lipoma-like SFT, atypical and malignant SFT, meningeal hemangiopericytoma, and infantile hemangiopericytoma. ${ }^{2}$ GCRSFTs mainly occur in the orbital region and rarely in the nasopharynx. To our knowledge, GCRSFT in the nasopharynx has not been reported.

Most SFTs present nearly as asymptomatic slow-growing masses. Large tumors can present with local symptoms due to compression. It is reported that about a quarter of patients develop paraneoplastic syndrome. Hypoglycemia could be a sign of paraneoplastic syndrome, which is mainly caused by an elevated level of insulin-like growth factor. Further, large SFTs (ie, with dimeters greater than $10 \mathrm{~cm}$ ) or SFTs with a high mitotic rate are often accompanied by reactive hypoglycemia. ${ }^{13}$ In our case, the tumor diameter was $3.9 \mathrm{~cm}$, but no hypoglycemia was observed, which is consistent with the literature. Moreover, due to its narrow space, SFT in the nasopharynx often compresses the eustachian tube, causing secretory middle ear inflammation. ${ }^{6-10}$ Ferrario et $\mathrm{al}^{9}$ reported a case of conventional nasopharyngeal SFT with right ear canal obstruction as the first symptom. Clinical examination revealed the presence of secretory otitis media. In our case, the patient did not have these symptoms, which made detection of the disease very difficult.

SFTs are highly vascular and appear as vigorously enhancing on both enhanced CT and MR images. These tumors are usually heterogeneous, with hypervascular areas showing early intense enhancement, hypercellular areas showing moderate enhancement, and areas of necrosis or of cystic or myxoid degeneration showing no enhancement. In addition, the hypercellular areas demonstrate persistent enhancement in the venous and delayed phases. ${ }^{14}$ In our case, the tumor was vigorously enhancing on enhanced CT image, and the hypercellular areas showed persistent enhancement in the venous phase, which is consistent with the literature. However, none of these imaging methods can achieve accurate diagnosis, and thus the final diagnosis is based on surgical resection and pathological examination.

GCRSFT was formerly known as GCA, and scattered multinucleated giant cells are usually located in the pseudovascular spaces, a characteristic finding of this rare tumor. ${ }^{2}$ IHC is essential in differentiating these tumors from other spindle-cell neoplasms. Positivity for CD34, CD99, and BCL-2 is an indicator of SFTs. Although the etiology of SFT remains largely unknown, the pathogenesis seems to be related to a NAB2-STAT6 fusion gene resulting from a paracentric inversion on chromosome $12 \mathrm{q} 13$. The incidence of this gene fusion has been reported to occur in more than $90 \%$ of SFTs. Thus, some researchers have concluded that this fusion is the primary pathogenic event contributing to SFT genesis. ${ }^{15}$ Nuclear staining for STAT6 by IHC was recently shown to be a highly sensitive and specific marker for SFT, which is diagnostically very valuable as conventional cytogenetic methods cannot detect the intrachromosomal NAB2-STAT6 fusion. ${ }^{16}$

Owing to similarities in their pathological features, such as spindle-shaped cells, myxoid matrix, widely distributed blood vessels, and multinucleated giant cells interspersed with collagen fibers, SFT can easily be misdiagnosed as GCF or nasopharyngeal fibroangioma (NA). However, the biological behaviors, treatment, and prognosis of these diseases are quite different, emphasizing the need for accurate identification. On microscopic examination, GCF shows a unique combination of spindle-cell patterns, pleomorphic and multinucleated giant cells, myxoid areas, and distinctive pseudovascular spaces. ${ }^{17}$ This histological manifestation was similar to that of our case, and thus differential diagnosis was made based on IHC. The most important and valuable positive markers for SFT are CD34, CD99, BCL-2, and STAT6. Geramizadeh et $\mathrm{al}^{18}$ demonstrated CD34 positivity in 95$100 \%$ of cases. In addition, nuclear staining for STAT6 by IHC has been shown to be a highly sensitive and specific marker for SFT, which is diagnostically very valuable as conventional cytogenetic methods cannot detect the intrachromosomal NAB2-STAT6 fusion. Han et $\mathrm{al}^{19}$ demonstrated that the sensitivity of STAT6 IHC is $96.2 \%$. In our case, the tumor cells were positive for CD34, CD99, and BCL-2, and STAT6 showed partially flaky nuclear positivity. Moreover, GCF affects predominantly children, while our patient is an adult. Therefore, for the current case, we could rule out GCF. NA is a benign but aggressive tumor of unknown etiology, typically occurring in adolescent males, while SFT typically occurs in middle-aged adults. NA is characterized by a fibrocollagenous stroma containing numerous variably sized, irregularly shaped vessels bearing an appearance resembling that in SFT. However, these neoplasms lack multinucleated giant cells, while the constituent stromal cells also lack CD34 and STAT6 immunoreactivity, which helped rule out NA as well.

Endoscopic endonasal surgery is ideally suited for the resection of SFTs in the nasal cavity. One of the challenges of an endoscopic approach is the setting of sizable tumors and/or bleeding that may obscure visualization and lead to 
incomplete resection. ${ }^{20}$ Since SFTs are rare, data on the use of pre- or postoperative therapy (radiotherapy (RT) or systemic treatments) are very limited, though responses observed in patients with advanced disease clearly support the use of RT in selected patients. Adriamycin or a combination of cyclophosphamide, vincristine, doxorubicin, and dacarbazine has also been considered to be the most effective chemotherapeutic treatment for SFTs, but they have not been shown to prolong overall survival. ${ }^{21}$ Studies have also demonstrated that preoperative embolization may be employed prior to surgical resection for highly vascular tumors to shrink the tumor and to prevent bleeding during the surgery. ${ }^{22}$ Immunotherapy, for example with interferon, may also be effective. ${ }^{23}$ In our case, angiography revealed a hypervascular tumor fed by branches of the left carotid artery. Hence, embolization of the feeding arteries was performed, and then the tumor was endoscopically resected without adjuvant treatments, such as RT or chemotherapy. The tumor was completely excised, the postoperative course was uneventful, and no recurrence was observed 14 months after surgery.

SFTs are distinct fibroblastic neoplasm of intermediate biological potential, the clinical behaviors of SFTs are unpredictable. Despite mostly following a favorable course, prognostication for SFT is notoriously difficult because of the propensity for late relapse or even metastasis in 10-40\% of cases, ${ }^{12}$ which prompts several proposed schemes as factors for risk stratification. Demicco et $\mathrm{al}^{24}$ analyzed 110 cases of SFT and developed a 3-tier risk stratification model based on patient age, tumor size, and mitotic counts. In their study, patients older than 55 years, with tumors greater than $15 \mathrm{~cm}$, and mitotic counts greater than 4 mitoses/10 HPFs had the highest risk of metastasis and tumor-related death. Moreover, the literature shows that local recurrence is significantly higher in patients with positive resection margins and that metastasis frequency is significantly higher in patients with tumors $>10 \mathrm{~cm}$. In addition, poor histopathological differentiation, deep tumor locations, TERT promoter and/or TP53 mutations, and nonsurgical treatment are also reportedly adverse prognostic factors. ${ }^{12}$ The high rate of local recurrence underscores the intermediate malignant potential of SFTs and the need for long-term follow-up.

In conclusion, our findings demonstrate the full morphologic spectrum of GCRSFTs, recognizing an expanded anatomic range. Although imaging tests could not achieve accurate diagnosis, they provided the first clue to the identification of the tumor and depicted the extent of local and invasion into adjacent structures. The final diagnosis was made based on pathological and immunohistochemical examinations. Preoperative arterial embolization, RT, and chemotherapy are essential for a successful complete surgical resection of SFTs. As SFT has a malignant potential, careful follow-up to detect potential local recurrence or metastasis is highly recommended.

\section{Consent to Publish}

Written informed consent was obtained from the patient for publication of this case report and the accompanying images. The images did not contain the patient records and information. This study was approved by the Clinical Research Ethics board of the First Affiliated Hospital, Shihezi University School of Medicine.

\section{Acknowledgments}

This work was supported by grants from the Professor Li-Juan Pang, the International Cooperation Projects of Shihezi University (grant nos. GJHZ201710, GJHZ201805), and the National Natural Science Foundation of China (grant no. 81860471).

\section{Disclosure}

The authors report no conflicts of interest in this work.

\section{References}

1. Davanzo B, Emerson RE, Lisy M, et al. Solitary fibrous tumor. Transl Gastroenterol Hepatol. 2018;3:94. doi:10.21037/tgh.2018.11.02

2. Organization WH. WHO classification of tumors of soft tissue and bone. IARC Press. 2013;468.

3. Dei Tos AP, Seregard S, Calonje E, et al. Giant cell angiofibroma. A distinctive orbital tumor in adults. Am J Surg Pathol. 1995;19 (11):1286-1293.

4. Guillou L, Gebhard S, Coindre JM. Orbital and extraorbital giant cell angiofibroma: a giant cell-rich variant of solitary fibrous tumor? Clinicopathologic and immunohistochemical analysis of a series in favor of a unifying concept. Am J Surg Pathol. 2000;24(7):971-979. doi:10.1097/00000478-200007000-00008

5. Sigel JE, Fisher C, Vogt D, et al. Giant cell angiofibroma of the inguinal region. Ann Diagn Pathol. 2000;4(4):240-244. doi:10.1053/ adpa.2000.8129

6. Zheng WJ, Zhang H. [Solitary fibrous tumor in the nasopharynx: a case report]. Zhonghua Er Bi Yan Hou Tou Jing Wai Ke Za Zhi. 2017;52(2):117-119. doi:10.3760/cma.j.issn.1673-0860.2017.02.012. Chinese.

7. Rizzo S, Giunta AA, Pennacchi A. Sinonasal and rhinopharyngeal solitary fibrous tumour: a case report and review of the literature. Acta Otorhinolaryngol Ital. 2015;35(6):455-458. doi:10.14639/0392100x-163813

8. Parghane RV, Agrawal K, Mittal BR, et al. 68Ga DOTATATE PET/CT imaging of a solitary fibrous tumor of the nasopharynx. Clin Nucl Med. 2014;39(8):e382-383. doi:10.1097/rlu.0000000000000274

9. Ferrario F, Piantanida R, Spriano G, et al. [Solitary fibrous tumor of the nasopharynx. Apropos of a case]. Ann Otolaryngol Chir Cervicofac. 1997;114(3):71-75. French. 
10. Job A, Walter N, David TM. Solitary fibrous tumor of the nasopharynx. J Laryngol Otol. 1991;105(3):213-214. doi:10.1017/ s0022215100115397

11. Künzel J, Hainz M, Ziebart T, et al. Head and neck solitary fibrous tumors: a rare and challenging entity. Eur Arch Otorhinolaryngol. 2016;273(6):1589-1598. doi:10.1007/s00405-015-3670-1

12. Huang SC, Huang HY. Solitary fibrous tumor: an evolving and unifying entity with unsettled issues. Histol Histopathol. 2019;34 (4):313-334. doi:10.14670/hh-18-064

13. Han G, Zhang Z, Shen X, et al. Doege-Potter syndrome: a review of the literature including a new case report. Medicine (Baltimore). 2017;96(27):e7417. doi:10.1097/MD.0000000000007417

14. Li XM, Reng J, Zhou P, et al. Solitary fibrous tumors in abdomen and pelvis: imaging characteristics and radiologic-pathologic correlation. World J Gastroenterol. 2014;20(17):5066-5073.

15. Robinson DR, Wu Y-M, Kalyana-Sundaram S, et al. Identification of recurrent NAB2-STAT6 gene fusions in solitary fibrous tumor by integrative sequencing. Nat Genet. 2013;45(2):180-185. doi:10.1038/ng.2509

16. Yoshida A, Tsuta K, Ohno M, et al. STAT6 immunohistochemistry is helpful in the diagnosis of solitary fibrous tumors. Am J Surg Pathol. 2014;38(4):552-559. doi:10.1097/PAS.0000000000000137

17. Jo VY, Fletcher CDM. WHO classification of soft tissue tumours: an update based on the 2013 (4th) edition. Pathology. 2014;46 (2):95-104. doi:10.1097/PAT.0000000000000050
18. Geramizadeh B, Marzban M, Churg A. Role of immunohistochemistry in the diagnosis of solitary fibrous tumor, a review. Iran J Pathol. 2016;11(3):195-203.

19. Han Y, Zhang Q, Yu X, et al. Immunohistochemical detection of STAT6, CD34, CD99 and BCL-2 for diagnosing solitary fibrous tumors/hemangiopericytomas. Int $J$ Clin Exp Pathol. 2015;8 (10):13166-13175.

20. Janjua A, Sklar M, Macmillan C, et al. Endoscopic resection of solitary fibrous tumors of the nose and paranasal sinuses. Skull Base. 2011;21(2):129-134. doi:10.1055/s-0031-1275259

21. Kawamura S, Nakamura T, Oya T, et al. Advanced malignant solitary fibrous tumor in pelvis responding to radiation therapy. Pathol Int. 2007;57(4):213-218. doi:10.1111/j.1440-1827.2007.02083.x

22. Yokoyama Y, Hata K, Kanazawa T, et al. Giant solitary fibrous tumor of the pelvis successfully treated with preoperative embolization and surgical resection: a case report. World J Surg Oncol. 2015;13(1):164. doi:10.1186/s12957-015-0578-6

23. Cuello J, Brugés R. Malignant solitary fibrous tumor of the kidney: report of the first case managed with interferon. Case Rep Oncol Med. 2013;2013:564980.

24. Demicco EG, Park MS, Araujo DM, et al. Solitary fibrous tumor: a clinicopathological study of 110 cases and proposed risk assessment model. Mod Pathol. 2012;25(9):1298-1306. doi:10.1038/ modpathol.2012.83

\section{Publish your work in this journal}

OncoTargets and Therapy is an international, peer-reviewed, open access journal focusing on the pathological basis of all cancers, potential targets for therapy and treatment protocols employed to improve the management of cancer patients. The journal also focuses on the impact of management programs and new therapeutic agents and protocols on patient perspectives such as quality of life, adherence and satisfaction. The manuscript management system is completely online and includes a very quick and fair peer-review system, which is all easy to use. Visit http://www.dovepress.com/ testimonials.php to read real quotes from published authors. 